Project 1020166

\title{
In Situ Immobilization of Uranium in Structured Porous Media via Biomineralization at the Fraction/Matrix Interface
}

\author{
Roden, Eric E. \\ University of Alabama
}

\begin{abstract}
RESULTS TO DATE: The major objectives of the University of Alabama component of this project are to (1) characterize the chemical composition (mainly iron and uranium abundance and redox speciation) of FRC Area 2 sediments; (2) assess the potential for stimulation of microbial Fe(III) and U(VI) reduction in slurries of Area 2 sediments; and (3) analyze the response of microbial community structure to biostimulation, specifically with regard to the abundance and diversity of dissimilatory metal-reducing bacterial (DMRB) populations. As an inclusive working hypothesis, we anticipate that it will be possible to stimulate microbial metal reduction in Area 2 sediment depth strata containing substantial quantities of $\mathrm{Fe}(\mathrm{III})$ oxides and $\mathrm{U}(\mathrm{VI})$, and that a major enrichment in known DMRB (e.g. Geobacteraceae and related organisms) will take place in response to biostimulation. Information on rates of microbial metabolism, patterns of $\mathrm{Fe} / \mathrm{U}$ biotransformation, and microbial community response obtained in the slurry experiments will be used to constrain preliminary numerical simulations of the field-scale biostimulation experiment, and to provide molecular (e.g. 16S rRNA/rDNA) targets for assessing the response of DMRB activity to in situ biostimulation. Our progress to date on the above objectives is summarized below.
\end{abstract}

\section{Chemical analysis of Area 2 sediments}

We have analyzed the abundance of solid-phase iron (Fe(II), amorphous Fe(III), and total Fe(III) oxide) and uranium $(\mathrm{U}(\mathrm{VI})$ and residual $\mathrm{U})$ in a total of 8 cores from the Area 2 field site (see http://bama.ua.edu/ eroden/NABIRFRCProject/NABIR2005PIMeetingBreakoutFieldResearch.htm). The analyses revealed a distinct enrichment in $\mathrm{U}(\mathrm{VI})$ (and total $\mathrm{U}$ ) at the base of the fill zone, with the zone of $\mathrm{U}$ enrichment extending 1-2 ft above and ca. $1 \mathrm{ft}$ below the $1 \mathrm{ft}$ deep layer of gravel located at the fillsaprolite interface for depth profiles of $\mathrm{Fe}$ and $U$ abundance). These results lead us to speculate that a major source of $\mathrm{U}(\mathrm{VI})$ input to Area 2 groundwaters (e.g. as documented by extensive monitoring of groundwater geochemistry at well GW835) is diffusive mass transfer of $U$ from U-enriched zones on either side of (i.e. above and below) the high-flow gravel layer. Based on this assessment, we have tentatively targeted the 15-20 ft depth interval for the in situ biostimulation experiment. We anticipate that diffusive/advective input of electron donor to U-enriched sediments on either side of (as well as within) the gravel layer will lead to reduction of $\mathrm{U}(\mathrm{VI})$ (both aqueous and sorbed), thus reducing the input of $U$ to the high-flow gravel layer. The Fe extraction analyses revealed the presence of relatively high concentrations of $\mathrm{Fe}(\mathrm{III})$ oxide in sediments above and below the gravel layer, which should provide an ample source of electron-accepting capacity for growth and maintenance of DMRB populations. We are currently engaged in a detailed baseline physiochemical characterization ( $\mathrm{Fe} / \mathrm{U}$ abundance and speciation, sediment grain size, $\mathrm{pH}$ ) of sediments in the vicinity of the gravel layer at Area 2 (obtained from geoprobe cores) which will be repeated on cores collected after the in situ biostimulation experiment scheduled for summer 2005. Pre- and post-biostimulation sediment samples will be transmitted to PNNL for microscopic/spectroscopic analysis of microscale mineral phase associations by John Zachara and colleagues.

\section{Sediment slurry experiments}

In the summer and fall of 2003 we conducted a preliminary assessment of the potential for stimulation of $\mathrm{Fe}(\mathrm{III})$ and $\mathrm{U}(\mathrm{VI})$ reduction in sediments from below the fill-saprolite interface (i.e. sediments from ca. 23$26 \mathrm{ft}$ depth) using ethanol $(10 \mathrm{mM})$ as the electron donor. These experiments were conducted when we were still targeting the intact saprolite for the in situ biostimulation experiment. The results indicated that all the sediments tested (6 depth intervals each from cores FWB 201 and 202) showed positive potential for stimulation of $\mathrm{Fe}$ (III) oxide reduction, as indicated by changes in the ratio of $\mathrm{Fe}(\mathrm{II})$ to total $\mathrm{Fe}$ in $0.5 \mathrm{M}$ $\mathrm{HCl}$ extracts of ethanol-amended vs. non-amended slurries. Unfortunately, the abundance of $\mathrm{U}(\mathrm{VI})$ was 
too low in these sediments to obtain reliable estimates of the potential for $\mathrm{U}(\mathrm{VI})$ reduction. However, experiments in which ca. $100 \mathrm{mmol} \mathrm{g-1}$ (approximately equal to the maximum concentration of $\mathrm{U}(\mathrm{VI})$ observed in sediments from the fill zone at Area 2) of exogenous $\mathrm{U}(\mathrm{VI})$ was added (as uranyl-acetate) to the sediment slurries after 96 days of preincubation indicated that the biostimulated sediments were capable of carrying out near-complete $\mathrm{U}(\mathrm{VI})$ reduction, as indicated by an average value of 0.3 for the ratio $(\mathrm{VI})$ to total $\mathrm{U}$ after ca. 2.5 months of incubation. In contrast, the unstimulated slurries showed much lower $\mathrm{U}(\mathrm{VI})$ reduction potential, as indicated by an average $\mathrm{U}(\mathrm{VI})$ :total $\mathrm{U}$ ratio of ca. 0.8 . Together these findings provide convincing preliminary evidence that it is possible to stimulate coupled in situ bioreduction of $\mathrm{Fe}(\mathrm{III})$ and $\mathrm{U}(\mathrm{VI})$ in Area 2 sediments.

In order to assess the potential for microbial reduction of endogenous $\mathrm{U}(\mathrm{VI})$ in Area 2 sediments, slurries of sediment from the zone of maximum U(VI) concentration in core FWB 201 were inoculated with ca. 108 cells $\mathrm{mL}-1$ of acetate/fumarate-grown Geobacter sulfurreducens cells. The reason for using the pure culture was that the sediments used had been exposed to air and were completely dry, which led us to anticipate that endogenous DMRB populations would no longer be active. Interestingly, this speculation was incorrect, as both the G. sulfurreducens-amended and unamended slurries showed reduction of ca. $60 \%$ of the endogenous $\mathrm{U}(\mathrm{VI})$ after ca. 1 month of incubation. Although the reason for the incomplete reduction of $\mathrm{U}(\mathrm{VI})$ observed in this experiment is not yet clear, other recent NABIR-funded research at $\mathrm{UA}^{*}$ has demonstrated the potential for $\mathrm{U}(\mathrm{VI})$ to become associated with surface sites in natural sediments at which both enzymatic and abiotic (i.e. Fe(II)-catalyzed) reduction is limited. Controls on enzymatic and chemical reduction of solid-associated $\mathrm{U}(\mathrm{VI})$ in Area 2 sediments will be addressed in detail in the new Burgos et al. NABIR project (Integrative Studies element).

*Jeon, B.H., S.D. Kelly, K.M. Kemner, M.O. Barnett, W.D. Burgos, B.A. Dempsey, E.E. Roden. 2004. Microbial reduction of $\mathrm{U}(\mathrm{VI})$ at the solid-water interface. Environ. Sci. Technol. 38:5649-5655. Jeon, B.H., S.D. Kelly, K.M. Kemner, M.O. Barnett, W.D. Burgos, B.A. Dempsey, E.E. Roden. 2005. Chemical reduction of $\mathrm{U}(\mathrm{VI})$ by $\mathrm{Fe}(\mathrm{II})$ at the solid-water interface of natural and synthetic iron(III) oxides. Environ. Sci. Technol. In press.

In spring/summer 2004, a detailed assessment of terminal electron acceptor metabolism and U(VI) reduction by native microflora was conducted with slurries of $U$-enriched Area 2 sediment from core FWB 215. As in the case of the experiment with G. sulfurreducens, this experiment was conducted with dried, pulverized sediment so as to facilitate sampling of the slurry by syringe and needle. However, instead of being inoculated with pure culture cells, the slurries were inoculated with a small (ca. $5 \%$ vol:vol) quantity of a suspension of undried sediment from the same depth interval in order to introduce a healthy natural microflora. The aqueous phase of the slurries was designed to match the groundwater geochemistry at Area 2, and thus contained ca. $1 \mathrm{mM}$ of both nitrate and sulfate as alternative electron acceptors (relative to $\mathrm{Fe}(\mathrm{III})$ and $\mathrm{U}(\mathrm{VI})$ reduction). Concentrations of various aqueous and solid-phase species were followed over time during a ca. 2-month incubation period. The results (see http://bama.ua.edu/ eroden/NABIRFRCProject/NABIR2005PIMeetingBreakoutFieldResearch.htm) demonstrated the classical pattern of electron acceptor consumption over time: nitrate was consumed first, followed by reduction of bioavailable Fe(III) oxide (which accounted for only ca. $20 \%$ of total Fe(III) oxide content of the slurry), and then by reduction of sulfate. Methane production then ensued after a ca. 1 week lag period. The results indicated that ethanol was oxidized directly to $\mathrm{CO} 2$ during the period of nitrate reduction, whereas ethanol appeared to be partially oxidized to acetate during Fe(III) and sulfate reduction, as evidenced by the accumulation of significant quantities of acetate. The acetate was converted to $\mathrm{CH} 4$ and $\mathrm{CO} 2$ during the methanogenic phase of the experiment. A very gradual reduction of nitrate was observed in non-ethanol-amended slurries, indicating the presence of only small quantities of endogenous labile organic matter in the sediment. $\mathrm{U}(\mathrm{VI})$ reduction took place mainly during the period of $\mathrm{Fe}(\mathrm{III})$ reduction (between days 5-10 of the experiment); only minor changes in the relative abundance $\mathrm{U}(\mathrm{VI})$ were observed during the ensuing sulfate-reducing and methanogenic phases. No $\mathrm{U}(\mathrm{VI})$ reduction was observed in the non-ethanol-amended slurries. Only ca. $60 \%$ of the $\mathrm{U}(\mathrm{VI})$ content of the sediment was reduced in the ethanol-amended slurries. Experiments are underway to assess whether the cessation of $\mathrm{U}(\mathrm{VI})$ reduction can be attributed to geochemical or microbial-physiological reasons. 


\section{Analysis of microbial community in biostimulated sediments}

At present, our primary efforts toward this objective involve analysis of the evolution of microbial community structure in the Area 2 sediment slurries (described above) which demonstrated a temporal sequence of different terminal electron-accepting processes. The goal of these analyses will be to link changes in microbial metabolism (as revealed by electron acceptor consumption and end-product formation) with changes in microbial community composition, e.g. in the relative abundance of key physiological functional groups such as nitrate-reducing, Fe(III)-reducing, sulfate-reducing, and methanogenic microorganisms. We have obtained PCR-amplifiable 16S rDNA, and RT-PCR amplifiable 16S rRNA, from six different time points in the ethanol-amended slurries: one at time zero (to characterize initial community structure), one during the nitrate reduction phase, two during the $\mathrm{Fe}(\mathrm{III}) / \mathrm{U}(\mathrm{VI})$ reduction phase, one during the sulfate reduction phase, and one during the methanogenic phase. Our plan is to analyze the 16S rDNA and rRNA in parallel, initially via denaturing gradient gel electrophoresis (DGGE) using published universal bacterial and archeal primer sets. Major bands on DGGE gels will be excised and sequenced to provide insight into predominant phylotypes present during the different metabolic phases of the experiment. Clone libraries will be generated as necessary (from PCR-amplified 16S rDNA and RT-PCR amplified 16S rRNA) to obtain more detailed information on microbial community structure, particularly during the $\mathrm{Fe}(\mathrm{III}) / \mathrm{U}(\mathrm{VI})$ reduction phase. The results of these analyses will provide useful predictors of changes in microbial community structure that are likely to be observed in groundwater and sediment samples from the in situ biostimulation experiment. Such samples will be analyzed using the techniques currently being implemented for the sediment slurry analyses.

An additional line of inquiry involves utilization of the microbead array system being developed by Darrell Chandler and colleagues at Argonne National Laboratory (ANL) for high-throughput analysis of DMRB populations in anaerobic sediments and groundwater. The phylogenetic design of the current DMRB microbead array system was initially developed by Chandler and colleagues, and modified to include additional DMRB phylogenies during a sabbatical visit by E. Roden to PNNL during January-May 2002 (prior to Chandler?s move to ANL in June 2002). Preliminary analysis of 16S rRNA obtained from acetate-stimulated Rifle groundwater samples (provided by P. Long of PNNL) and acetate-stimulated Oyster, VA sediments (provided by E. Roden) has demonstrated the ability of the bead array to respond selectively to DMRB $16 \mathrm{~S}$ rRNA. Ongoing NABIR-sponsored work by Chandler and colleagues seeks to refine the ability of the array to provide quantitative estimates of DMRB 16S rRNA and/or 16S rDNA. In order to provide a comprehensive test of the ability of the array system to detect DMRB populations in biostimulated sediments, we are arranging to provide Chandler with a variety of nucleic acid samples from the slurry experiment described above, including (i) PCR-amplified 16S rDNA, (ii) RT-PCR amplified 16S rRNA, and (iii) native 16S rRNA. These different nucleic acid samples will be analyzed using the microbead array, and the results will be compared directly with those obtained from the DGGE and clone library work being conducted at UA.

Finally, we have engaged in a collaboration with Aaron Peacock and colleagues in D.C. White?s laboratory at the University of Tennessee on PLFA (both bulk and 13C-labeled compound specific) analysis of samples from the Area 2 sediment slurry experiment. The samples were collected at the same six time points as those for molecular analysis so as to afford a direct comparison of the methodologies. The GC-MS and GC-MS-IRMS have been completed and we are in the process of analyzing the data.

DELIVERABLES: Publications:

Roden, E.E. and T.D. Scheibe. 2005. Conceptual and numerical model of uranium(VI) reductive immobilization in fractured subsurface sediments. Chemosphere. 59:617-628.

Presentations:

Mohanty, S., B. Kollah, and E. Roden. Biogeochemical processes in ethanol-stimulated subsurface sediments. American Society for Microbiology General Meeting, May 2005. 
Roden, E., Mohanty, S., B. Kollah, T. Scheibe, Y. Fang, and S. Brooks. Numerical simulation of terminal electron-accepting processes in ethanol-stimulated subsurface sediments. American Society for Microbiology General Meeting, May 2005.

Roden, E.E. and T.D. Scheibe. 2002. Multiple pore region model of uranium(VI) reductive immobilization in structured subsurface media. American Geophysical Union Fall Meeting, December 2002.

COLLABORATIONS: PNNL ORNL 